Original Article

\title{
ANTIMICROBIAL AGENT'S UTILIZATION AND COST PATTERN IN MEDICAL INTENSIVE CARE UNIT OF A TERTIARY CARE HOSPITAL
}

\section{SARTAJ HUSSAIN ${ }^{1}$, SURAJ SINGH YADAV ${ }^{2}$, KAMAL KUMAR SAWLANI ${ }^{3}$, KAUSER USMAN ${ }^{4}$, SANJAY KHATTRI ${ }^{5}$}

1,2,5Department of Pharmacology and Therapeutics King George's Medical University, Lucknow, 3,4Department of Medicine, King George's Medical University, Lucknow

Email: drsanjaykhattri@gmail.com

Received: 07 Mar 2021, Revised and Accepted: 09 Jun 2021

\section{ABSTRACT}

Objective: The objective of this study was to evaluate the utilization and cost pattern of AMAs (Antimicrobial Agents) in the Medical ICU of a tertiary care teaching hospital, and to determine the predictor of antimicrobial number per day.

Methods: A prospective cross-sectional study was carried out and a total of 101 patients were studied. The drugs were classified into different groups according to the World Health Organization's ATC (Anatomical Therapeutic Chemical) Classification System.

Results: The mean [95\% confidence interval (CI)] duration of ICU stay was 7.11 (5.70-8.52) days and the mortality rate in the ICU was $42.6 \%$. The AMAs DDD (Defined Daily Dose) per 100 patient days and number of AMAs per prescription were 296.64 and 2.65, respectively. Piperacillintazobactam was the most commonly utilized AMAs followed by metronidazole, meropenem, fluconazole, and colistin. The mean number [95\% $\mathrm{CI}$ ] of AMAs, DDD, and cost (INR) per patient were 18.82 (14.05-23.59), 21.09 (15.36-26.81) and 25,827 (18,716-32,939) respectively. The AMAs constituted $88.53 \%$ of the total treatment cost. Meropenem was the most costly AMA (32.10\% of the total AMAs cost) followed by imipenemcilastatin (20.50\%), colistin (14.65\%), piperacillin-tazobactam (8.40\%), and clindamycin (4.47\%). The independent predictor for the antimicrobial number per day was acute physiology and chronic health evaluation II (APACHE-II) score at admission and nosocomial infections.

Conclusion: The AMAs, DDD per 100 patient days, and number per prescription were higher. This leads to a higher cost of AMAs per patient and the AMAs cost out of the total cost as compared to previous studies. We suggest, there is a need to formulate and implement an antimicrobial restriction policy.

Keywords: DDD (Defined daily dose), ATC (Anatomical therapeutic chemical), Antimicrobial utilization, ICU (Intensive care unit)

(C) 2021 The Authors. Published by Innovare Academic Sciences Pvt Ltd. This is an open access article under the CC BY license (https://creativecommons.org/licenses/by/4.0/) DOI: https://dx.doi.org/10.22159/ijpps.2021v13i8.41338. Journal homepage: https://innovareacademics.in/journals/index.php/ijpps.

\section{INTRODUCTION}

World Health Organization (WHO) has defined drug utilization research as "the marketing, distribution, prescription, and use of drugs in society, with special emphasis on the resulting medical, social, and economic consequences" [1].

The patients admitted to the medical intensive care units (ICUs) are generally seriously ill or require specialized care and close monitoring. They are predisposed to get infected either due to various invasive procedures or secondary to nosocomial infection. The antimicrobial agents (AMAs) utilization rate is high in ICUs as compare to the general wards [2]. Multiple broad-spectrum AMAs are usually administered empirically to these patients and this usually leads to the inappropriate use of AMAs [3-5]. The higher utilization and inappropriate use of AMAs lead to the development of antimicrobial resistance (AMR) in the ICUs $[4,5]$. The AMR is the major determinant of therapeutic outcomes [6]

The AMR is continuously increasing globally and leading cause of public health threats and economic consequences $[7,8]$. The rational utilization of AMAs will not only reduce the costs but also reduce the incidence of AMR that leads to a better prognosis [9].

There is limited data from Indian ICUs on antimicrobial agent's prescription, utilization patterns, and cost in Indian ICUs. Regular prescription audit and feedback can reduce the irrational use of AMAs in ICU. We have aimed to assess the utilization pattern and cost analysis of AMAs in the Medical ICU of a tertiary care teaching hospital.

\section{MATERIALS AND METHODS}

\section{Study subjects}

This study was a prospective observational study. It was conducted at 12 bedded Intensive Care Unit (ICU) of the Department of
Medicine at King George's Medical University, Lucknow. The study is approved by the institutional ethics committee (Reference code:

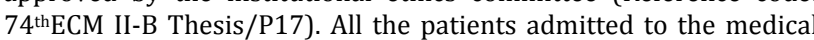
ICU, who were prescribed at least one antimicrobial agent, were included in the study. Those who did not give informed consent or gave incomplete data and patients who stayed for less than $24 \mathrm{~h}$ in the ICU, were excluded from the study. The data were collected prospectively for 3months $11 / 05 / 2016$ to $31 / 07 / 2016)$. Written informed consent was taken from the patients or parents/guardians of the patients. A total of 101 patients were recruited based on exclusion and inclusion criteria.

The demographic variables, vitals, acute physiology and chronic health evaluation II (APACHE II) score at admission, duration of ICU stay, and the diagnosis was recorded in the case record form. All drugs listed on the prescription were recorded. The dose, frequency, duration, and route of administration of all drugs were recorded until the patient got shifted to the ward, got discharged, or got expired. The drugs are given in infusions (barring AMAs), intravenous fluids, sedatives, atropine, and insulin, which were not included in the analysis.

The drugs were classified into different groups according to the WHO-ATC classification. Antimicrobials are all substances of ATC group J (anti-infectives for systemic use, including antibacterials for systemic use, antimycotics for systemic use, antimycobacterial, antivirals for systemic use, immune sera, immunoglobulin's, and vaccines) and group $\mathrm{P}$ (Antiparasitic products include antiprotozoals, anthelmintics, and ectoparasiticides) $[10,11]$

The following indicators were calculated:

1. DDD of each prescribed drug was calculated.

2. DDD per 100 patient days: Patient days are the number of days for which inpatients are hospitalized. The days of admission, but not 
the day of discharge, are counted as patient days. For example, if both the admission and discharge occur on the same day, this is counted as 1 patient day. For hospital inpatients, DDD/100 patient days provide a rough estimate of drug consumption.

$$
\text { DDD } / 100 \text { patient days }=\frac{\text { Total consumption in DDDs }}{\text { Number of patient days }} \times 100
$$

DU90\% index-the DU90\% was calculated by ranking the antimicrobial by volume of DDD, summing the DDD for these drugs, and then determining how many drugs accounted for $90 \%$ of drug use.

The brand name of drugs was decoded using the CIMS drug manual (Volume-6, Issue-67).

\section{Statistical analysis}

Percentage usage and DDD/100 Patient days were calculated. Continuous data are presented as mean (95\% CI) and were analyzed using the Mann-Whitney U test. A multiple regression binary logistic with forward conditional elimination was used to examine the effect of covariates on antimicrobial numbers per day and to identify independent predictors of the antimicrobial number per day. Covariates with $\mathrm{p} \leq 0.10$ in the respective univariate analysis were entered into these models. Results of binary logistic regression are reported as odds ratios with corresponding 95\% CI. A two-tailed $\mathrm{p}<0.05$ was considered statistically significant. All analyses were performed with SPSS statistical software package (version 20, IBM Inc., Armonk, NY, USA).

\section{RESULTS}

\section{Patient characteristics}

A total of 101 patients were included in the study. Of these 101 patients, $58(57.4 \%)$ were male and $43(42.6 \%)$ were female. The mean $(95 \% \mathrm{CI})$ age of the patients was 39.21 (35.12-43.30) years. The mean (95\% CI) APACHE II score at the admission of the patients was 17.88 (16.13-19.63). The total patient days were $718 \mathrm{~d}$ and the mean (95\% CI) length of stay (LOS) stay was 7.11 (5.70-8.52) days. The comorbidity was present in $51(50.50 \%)$ patients. Out of 101 patients, $63(62.4 \%)$ patients were on the ventilator at any time during the hospital stay. The nosocomial infection developed in 32 $(31.7 \%)$ patients. The mortality rate in the ICU was $42.6 \%$.

Respiratory illness (24.75\%) was the most common cause for admission in the ICU followed by shock/MODS (Multiple Organ Dysfunction Syndrome) (18.81\%), poisoning (14.85\%), central nervous system disease $(10.89 \%)$, gastrointestinal tract and hepatobiliary system (9.90\%), pyrexia (6.93\%), cardiovascular system disease (5.94\%), renal system disease (5.94\%) and endocrine system disease (1.98\%).

In 718 prescriptions of 101 patients, a total of 5015 drugs and 1901 AMAs were prescribed with an average of 6.98 drugs per prescription and 2.65 AMAs per prescription. The AMAs constituted $37.90 \%$ of the total number of drugs prescribed.

The total consumption of drugs in this study was 5,535.19 DDD, where antimicrobials (group J and P) constituted the most utilized single group with 2,129.90 DDD (38.47\%) of all drugs utilized and $3,405.29$ DDD (61.53\%) by other groups. The total consumption of drugs in DDD/100 patient days was 770.92, where antimicrobials (group J and P) constituted 296.64 DDD/100 patient days and 474.28 DDD/100 patient days by other groups.

The total drug cost in ICU was 2,946,513 INR, where antimicrobials (group J and P) constituted the costliest group with 2,608,591 INR (88.53\%) of all drug costs and 337,922 INR $(11.47 \%)$ by other groups. The total drug cost in terms of INR/100 patient days was 410,377 INR/100 patient days, where antimicrobials (group J and P) constituted 363,313 INR/100 patient days and 47,064 INR/100 patient days by other groups. The total drug and antimicrobials cost per patient was 29,173 and 25,827 INR per patient, respectively [table 1].

Table 1: Total drug and antimicrobial DDD, number, and cost per patient

\begin{tabular}{ll}
\hline Total drug DDD per patient & $54.80(41.19-68.41)$ \\
Antimicrobial DDD per patient & $21.09(15.36-26.81)$ \\
Total drug number per patient & $49.65(36.74-62.57)$ \\
Antimicrobial number per patient & $18.82(14.05-23.59)$ \\
Total drug cost per patient (INR) & $29,173(21,524-36,822)$ \\
Antimicrobial cost per patient (INR) & $25,827(18,716-32,939)$ \\
\hline
\end{tabular}

Values are expressed in mean (95\% confidence interval)

Table 2: Comparison of antimicrobial DDD, number, and cost per patient based on various factors

\begin{tabular}{|c|c|c|c|}
\hline Patients & Antimicrobials DDD per patient & Antimicrobial no per patient & Antimicrobials cost per patient \\
\hline Survived $(\mathrm{N}=58)$ & $14.26(9.65-18.87)$ & $13.45(9.13-17.77)$ & $18,223(11,007-25,440)$ \\
\hline Expired $(\mathrm{N}=43)$ & $30.30(18.64-41.96)$ & $26.07(16.69-35.45)$ & $36,083(22,740-49,426)$ \\
\hline$P$ value & $0.010^{*}$ & $0.006^{*}$ & $0.010^{*}$ \\
\hline Co-morbidity present $(\mathrm{N}=51)$ & $24.49(14.38-34.60)$ & $20.58(12.50-28.66)$ & $30,109(18,324-41,894)$ \\
\hline Co-morbidity absent $(\mathrm{N}=50)$ & $17.75(11.99-23.52)$ & $17.10(11.70-22.50)$ & $21,629(13,315-29,944)$ \\
\hline P value & 0.336 & 0.456 & 0.109 \\
\hline Ventilated $(\mathrm{N}=63)$ & $28.44(19.78-37.11)$ & $24.79(17.59-32.00)$ & $35671(25,083-46,260)$ \\
\hline Not ventilated $(\mathrm{N}=38)$ & $8.90(6.68-11.11)$ & $8.92(6.75-11.10)$ & $9507(6,114-12,900)$ \\
\hline $\mathrm{P}$ value & $0.001^{*}$ & $0.001^{*}$ & $0.001^{*}$ \\
\hline $\begin{array}{l}\text { Nosocomial infection } \\
\text { developed }(\mathrm{N}=32)\end{array}$ & $46.12(31.88-60.36)$ & $40.56(28.90-52.22)$ & $54668(38,522-70,814)$ \\
\hline $\begin{array}{l}\text { Nosocomial infection not } \\
\text { developed }(\mathrm{N}=69)\end{array}$ & $9.48(7.14-11.81)$ & $8.74(6.95-10.53)$ & $12452(75,22-17,832)$ \\
\hline$P$ value & $<0.001^{*}$ & $<0.001^{*}$ & $<0.001^{*}$ \\
\hline $\begin{array}{l}\text { APACHE II score } \leq 15 \\
(\mathrm{~N}=45)\end{array}$ & $10.67(6.88-14.47)$ & $10.51(6.87-14.14)$ & $13,884(6,620-21,148)$ \\
\hline APACHE II Score >15 $(n=56)$ & $29.45(20.02-38.90)$ & $25.50(17.73-33.27)$ & $35,424(24,443-46,405)$ \\
\hline$P$ value & $<0.001^{*}$ & $<0.001^{*}$ & $<0.001 *$ \\
\hline
\end{tabular}

Values are expressed in mean (95\% confidence interval)*Pvalue $<0.05$ is considered significant. NS: not significant. 
Table 3: AMAs consumption (Group J and P) measured in DDD

\begin{tabular}{|c|c|c|c|c|}
\hline ATC code & Antimicrobial groups & DDD & DDD/100PD & \% of total AMAs DDD \\
\hline J01AA12 & Tigecycline $\left(16^{\text {th }}\right)$ & 37.00 & 5.15 & 1.74 \\
\hline J01CR02 & Amoxicillin and enzyme inhibitor & 22.50 & 3.13 & 1.06 \\
\hline J01CR05 & Piperacillin-tazobactam (1st) & 209.43 & 29.17 & 9.84 \\
\hline J01DD04 & Ceftriaxone $\left(9^{\text {th }}\right)$ & 110.00 & 15.32 & 5.16 \\
\hline J01DD12 & Cefoperazone $\left(14^{\text {th }}\right)$ & 49.00 & 6.82 & 2.30 \\
\hline J01DH02 & Meropenem $\left(3^{\text {rd }}\right)$ & 189.00 & 26.32 & 8.87 \\
\hline J01DH51 & Imipenem-cilastatin $\left(7^{\text {th }}\right)$ & 140.75 & 19.60 & 6.61 \\
\hline J01FA10 & Azithromycin & 33.00 & 4.60 & 1.55 \\
\hline J01FF01 & Clindamycin $\left(6^{\text {th }}\right)$ & 150.67 & 20.98 & 7.07 \\
\hline J01GB01 & Tobramycin $\left(12^{\text {th }}\right)$ & 78.00 & 10.86 & 3.66 \\
\hline J01GB06 & Amikacin $\left(11^{\text {th }}\right)$ & 86.75 & 12.08 & 4.07 \\
\hline J01MA12 & Levofloxacin $\left(10^{\text {th }}\right)$ & 91.50 & 12.74 & 4.30 \\
\hline J01MA14 & Moxifloxacin (15 $\left.{ }^{\text {th }}\right)$ & 43.00 & 5.99 & 2.02 \\
\hline J01XA01 & Vancomycin & 21.40 & 2.98 & 1.00 \\
\hline J01XA02 & Teicoplanin ( $\left.8^{\text {th }}\right)$ & 122.00 & 16.99 & 5.73 \\
\hline J01XB01 & Colistin ( $\left.5^{\text {th }}\right)$ & 167.67 & 23.35 & 7.87 \\
\hline J01XD01 & Metronidazole ( $\left.2^{\text {nd }}\right)$ & 198.87 & 27.70 & 9.34 \\
\hline J01XX08 & Linezolid $\left(13^{\text {th }}\right)$ & 71.00 & 9.89 & 3.33 \\
\hline \multirow[t]{3}{*}{ J02AC01 } & Fluconazole ( $\left.4^{\text {th }}\right)$ & 172.00 & 23.96 & 8.08 \\
\hline & Others & 136.37 & 19.01 & 6.40 \\
\hline & Total & 2129.91 & 296.64 & 100.00 \\
\hline
\end{tabular}

Others represent the antimicrobial agents with less than $1 \%$ of total DDD.

Table 4: AMAs cost (Group J and P) measured in Indian Rupees (INR)

\begin{tabular}{|c|c|c|c|c|}
\hline ATC Code & Antimicrobial group & Total cost & Total cost/100PD & $\%$ of total AMAs Cost \\
\hline J01CR05 & Piperacillin-tazobactam ( $\left.4^{\text {th }}\right)$ & $219,062.29$ & $30,510.07$ & 8.40 \\
\hline J01DD12 & Cefoperazone $\left(8^{\text {th }}\right)$ & $60,270.00$ & $8,394.15$ & 2.31 \\
\hline J01DD62 & Cefoperazone-sulbactam & $29,754.00$ & $4,144.01$ & 1.14 \\
\hline J01DH02 & Meropenem $\left(1^{\text {st }}\right)$ & 837,270 & $116,611.42$ & 32.10 \\
\hline J01DH51 & Imipenem-cilastatin (2nd $)$ & $534,850.00$ & $74,491.64$ & 20.50 \\
\hline J01FF01 & Clindamycin ( $\left.5^{\text {th }}\right)$ & $116,616.00$ & $16,241.78$ & 4.47 \\
\hline J01XA01 & Vancomycin & $29,232.40$ & $4,071.36$ & 1.12 \\
\hline J01XA02 & Teicoplanin $\left(6^{\text {th }}\right)$ & $108,702.00$ & $15,139.55$ & 4.17 \\
\hline J01XB01 & Colistin $\left(3^{\text {rd }}\right)$ & $382,280.00$ & $53,242.34$ & 14.65 \\
\hline J01XX08 & Linezolid (9th) & $49,842.00$ & $6,941.78$ & 1.91 \\
\hline \multirow[t]{3}{*}{ J05AB01 } & Aciclovir $\left(7^{\text {th }}\right)$ & $60,800.00$ & $8,467.97$ & 2.33 \\
\hline & Others & 179,912 & $25,057.45$ & 6.9 \\
\hline & Total & $2,608,591$ & $363,313.45$ & 100.00 \\
\hline
\end{tabular}

Others represent the antimicrobial agents with less than $1 \%$ of the total cost.

Table 5: Predictors of multiple antimicrobial prescribing using binary logistic regression analysis

\begin{tabular}{|c|c|c|c|c|c|c|}
\hline & \multicolumn{2}{|l|}{ Antimicrobial prescriptions } & \multicolumn{2}{|l|}{ Univariate } & \multicolumn{2}{|l|}{ Multivariate } \\
\hline Predictors & $\begin{array}{l}\leq 2 \text { antimicrobial number } \\
\text { per day number }(\%)\end{array}$ & $\begin{array}{l}>2 \text { antimicrobial number } \\
\text { per day number }(\%)\end{array}$ & OR $(95 \% \mathrm{CI})$ & p value & $\begin{array}{l}\text { Addjusted OR } \\
\text { (95\% CI) }\end{array}$ & p value \\
\hline \multicolumn{7}{|c|}{ P } \\
\hline$\leq 45$ & $37(58.7)$ & $26(41.3)$ & 3.49 & $0.004^{*}$ & -- & -- \\
\hline$>45$ & $11(28.9)$ & $27(71.1)$ & $(1.47-8.27)$ & & & \\
\hline \multicolumn{7}{|l|}{ Gender } \\
\hline Male & $25(43.1)$ & $33(56.9)$ & 0.66 & 0.302 & -- & -- \\
\hline female & $23(53.5)$ & $20(46.5)$ & $(0.30-1.46)$ & & & \\
\hline \multicolumn{7}{|c|}{ APACHE II $\leq 15$} \\
\hline \multirow[t]{2}{*}{$>15$} & $33(73.3)$ & $12(26.7)$ & 7.52 & $<0.001^{*}$ & 5.70 & $<0.001^{*}$ \\
\hline & $15(26.8)$ & $41(73.2)$ & $(3.10-18.24)$ & & $(2.27-14.33)$ & \\
\hline \multicolumn{7}{|c|}{ Comorbidity } \\
\hline Absent & $30(58.8)$ & $21(41.2)$ & 2.54 & $0.023^{*}$ & -- & -- \\
\hline Present & $18(36.0)$ & $32(64.0)$ & $(1.14-5.67)$ & & & \\
\hline \multicolumn{7}{|l|}{ Ventilated } \\
\hline No & $22(57.9)$ & $16(42.1)$ & 1.96 & 0.107 & -- & -- \\
\hline Yes & $26(41.3)$ & $37(58.7)$ & $(0.87-4.43)$ & & & \\
\hline \multicolumn{7}{|c|}{ Nosocomial infection } \\
\hline No & $41(59.4)$ & $28(40.6)$ & 5.23 & $0.001^{*}$ & 3.24 & $0.028^{*}$ \\
\hline Yes & $7(21.9)$ & $25(78.1)$ & $(1.99-13.74)$ & & (1.14-9.22) & \\
\hline \multicolumn{7}{|c|}{ Length of stay } \\
\hline$\leq 7$ & $38(56.7)$ & $29(43.3)$ & 3.15 & $0.011^{*}$ & -- & -- \\
\hline$>7$ & $10(29.4)$ & $24(70.6)$ & $(1.30-7.60)$ & & & \\
\hline
\end{tabular}

Logistic regression analysis with the forward conditional elimination was used with entry critexia.d 0 pand a removal $\mathrm{p}>0.10{ }^{*}$ Significant $\mathrm{OR}=$ odd's ratio, $\mathrm{CI}=$ confidence interval, ${ }^{*}$ Pvalue $<0.05$ is considered significant. Input variables in Multivariate binary logistic regression analysis: Age, APACHE-II, Comorbidity, Nosocomial infection, and Length of stay. 
The antimicrobials DDD, number, and cost per patient was significantly higher in expired (vs. survived), ventilated (vs. not ventilated), patients who developed a nosocomial infection (vs. not developed nosocomial infection) and APACHE II score $>15$ (vs. APACHE II Score $\leq 15$ ) [table 2].

A total of 35 antimicrobial agents were prescribed. There were 16 AMAs in the DU 90\% segment out of 35 used AMAs. The DU90\% index placed piperacillin-tazobactam at 1stplace with 209.43 DDD (9.84\%). The metronidazole came $2^{\text {nd }}$ with 198.87DDD (9.34\%), followed by meropenem ( $\left.3^{\text {rd }}\right)$ with 189 DDD $(8.87 \%)$, fluconazole $\left(4^{\text {th }}\right)$ with 172 DDD $(8.08 \%)$, and colistin ( $\left.5^{\text {th }}\right)$ with $167.67 D D D(7.87 \%)$. The AMAs utilization in terms of DDD/100 patient days for piperacillintazobactam, metronidazole, meropenem, fluconazole, and colistin were $29.17,27.70,26.32,23.96$, and 23.35 , respectively [table 3 ].

The 9 AMAs constituted $90 \%$ of the total AMAs cost. Meropenem was the costliest AMA (32.10\% of the total AMAs cost) followed by imipenem-cilastatin (20.50\%), colistin (14.65\%), piperacillintazobactam (8.40\%), and clindamycin (4.47\%). The AMAs cost in terms of INR/100 patient days for meropenem, imipenem-cilastatin, colistin, piperacillin-tazobactam, and clindamycin were 116,611 INR/100 patient days, 74,491 INR/100 patient days, 53,242 INR/100 patient days, 30,510 INR/100 patient days, and 16,241 INR/100 patient days, respectively [table 4].

On analyzing the indication of antimicrobials therapy, it was found that out of 2129.91 DDD of AMAs, 1479.25 DDD (69.45\%) was prescribed empirically followed by definitive 590.80 DDD (27.74\%) and prophylactically 59.86 DDD $(2.81 \%)$.

On univariate binary logistic regression analysis, the significant factors for the antimicrobial number per day were age $<45 \mathrm{y}$, APACHE II score at admission $>15$, comorbidity, nosocomial infection, and length of stay $>7 \mathrm{~d}$. The multivariate analysis showed that the independent predictor for the antimicrobial number per day was the APACHE II Score at admission>15 and nosocomial infection [table 5].

\section{DISCUSSION}

Male preponderance $(57.4 \%)$ was observed in the present study and the male: female ratio was following the previous studies [12-15]. In contrast, a study had reported an equal percentage of male and female patients [16]. The mean age of the patients in our study was $39.21 \mathrm{y}$, which was less than the mean age reported previously $(44.62$ to 60.30 y) $[12-15,17,18]$. The mean $(95 \%$ CI) length of stay (LOS) in our study was $7.11(5.70-8.52)$ days which was comparable to the other studies $[13-15,17,19]$. In other studies, the mean LOS in ICU was found to be in the range of 4.0 to $7.3 \mathrm{~d}$. The mortality rate was found to be $42.6 \%$, which was slightly higher compared to other studies. In other studies, the mortality in ICU was found to be in the range of 12.0 to $39.5 \%$ [15-17]. But in a study conducted by Patel et al. (2013), the mortality rate in patients with medical indication was high $(71.58 \%)$ [13].

\section{Utilization of antimicrobial agent (quantitatively in DDD)}

The AMAs consumption rate was 296.64 DDD/100 patient days, much higher compared to the two Indian studies (36.52 and 148.97 DDD/100 patient-days) $[13,15]$. In a meta-analysis conducted by Bitterman et al. (2016), the antibacterial consumption was highest in intensive care units with a value of $156.3 \mathrm{DDD} / 100$ hospital days (95\% CI: 147.2 to 165.3 ) [20, ]. In the ICARE Project in 40 US hospitals, the antibiotic consumption rate in ICU ranged from 41.3 to 92.7 DDD per 100 patient days [21].

The total number of AMAs used was 35, out of them 16were in the DU90\% segment. Adeli et al. (2015) studied the antibiotics use patterns in intensive care units of five hospitals, the number of AMAs in the DU90\% segment ranged from 3 to 12 [22].

The most commonly utilized AMAs in our study were piperacillintazobactam followed by metronidazole, meropenem, fluconazole, and colistin [table 3]. In a study by Williams et al. (2011) from North India, the five most utilized AMAs were $3^{\text {rd }}$ generation cephalosporins, meropenem, metronidazole, levofloxacin, and ceftriaxone [18]. In a study by Anand et al. (2016) from South India, the five most utilized AMAs were ceftriaxone, piperacillin-tazobactam, metronidazole, linezolid, and amoxicillin-clavulanic acid [15].
In a study in 35 ICUs of Germany, the penicillins with a beta-lactamase inhibitor, quinolones, and second-generation cephalosporins were the most commonly utilized AMAs while a study from Latin America, the carbapenems (imipenem or meropenem), vancomycin, piperacillintazobactam, and broad-spectrum cephalosporins were the most frequently used AMAs [14, 23].

\section{Cost of antimicrobial agent}

The total cost of all drugs and AMAs used throughout the study period was 2,946,513 INR and 2,608,591 INR, respectively. The AMAs constituted $88.53 \%$ of the total cost. Meropenem constitutes the major portion of the total cost of all AMAs used (32.10\%) like other studies $[18,20-24]$ but in one study from Gujrat, the piperacillin-tazobactam constitute the major portion of the total cost of all AMAs used [15]. The top five AMAs utilized constitute $80.12 \%$ of the total AMA cost. The next four most expensive AMAs utilized were imipenem-cilastatin (20.50\%), colistin (14.65\%), piperacillin-tazobactam $(8.40 \%)$, and clindamycin $(4.47 \%)$. In other studies, AMAs cost ranged from $40 \%$ to $73.2 \%$ of the total cost $[12,13,18,25]$.

In our study, the total cost and the AMAs cost per patient were 29,173 INR (435.30\$) and 25,827 INR (385.37 \$), respectively [table 1]. In other Indian studies, the mean antimicrobial cost per patient was in the range of 1,958 to $4,364 \operatorname{INR}[15,18,25]$. But a study conducted in Maharashtra by Mangrulkar et al. (2012), the mean antimicrobial cost per patient was 39,328 INR [26].

The drug cost is enormously varied across the globe so comparisons of AMA's cost among countries may be deceptive. In our study AMA cost per 100 patient days was 363,313 INR. The daily AMAs cost in our study was 3,633 INR (54\$) which was lower as compared to studies conducted in Belgium (114€) and Turkey (89\$) [24, 27].

\section{Prescription of antimicrobial agent (frequency)}

In our study, a total of 5015 drugs and 1901 AMAs were prescribed in the 718 prescriptions, which was an average of 6.98 drugs per prescription and 2.65 AMAs per prescription, AMAs constituted $37.90 \%$ of the total number of drugs prescribed. In other studies, the mean number of drugs per prescription was in the range of 6.23 to $11.6[16,18,25,28]$. The mean number of AMAs per prescription from other studies was in the range of 1.73 to $2.09[15,18,24]$. The percentage of AMAs number out of total drugs in two Indian studies was $20.97 \%$ and $33.54 \%[18,25]$.

\section{CONCLUSION}

The AMAs consumption rate (DDD per 100 patient-days) was higher in the studied medical ICU. The number of AMAs per prescription was higher in our study compared to other studies. The cost of AMAs per patient and the AMAs cost out of the total cost was quite higher in comparison to the previous studies. The antimicrobials DDD, number, and cost per patient were significantly higher in expired (vs. survived), ventilated (vs. not ventilated) patients, and patients who developed a nosocomial infection (vs. not developed nosocomial infection). The APACHE-II score at admission and nosocomial infection was the independent predictor of antimicrobial number per day.

\section{RECOMMENDATIONS}

There is a need to formulate and implement a strict antimicrobial restriction policy. There should be a regular audit to increase adherence to policy/protocol. An antimicrobial stewardship program should be implemented. The possible inclusion of clinical pharmacologists and microbiologists in the auditing team can prove helpful in the rational use of AMAs.

\section{LIMITATIONS OF THE STUDY}

The period of the study was limited $(3 \mathrm{mo}$ ). We did not check the rationality of prescribed AMAs. The study was conducted in the medical ICU only and we did not include other ICUs (surgical/neonatal/pediatric) of the hospital. DDD values do not take into account the frequently encountered clinical situation of dose adjustments (hepatic impairment, renal impairment, etc.).

\section{ACKNOWLEDGMENT}

The authors are thankful to Mr. Durgesh Yadav for providing technical assistance during the study. 


\section{FUNDING}

Nil

\section{AUTHORS CONTRIBUTIONS}

1-Dr. Sartaj Hussain (MD): Collection, analysis, and interpretation of data, manuscript preparation.

2-Dr. Suraj Singh Yadav (PhD): Acquisition of data, analysis, manuscript writing.

3-Prof. Kamal Kumar Sawlani (MD): Interpretation of data, manuscript editing, clinical supervision.

4-Prof. Kauser Usman (MD): Interpretation of data, manuscript editing, clinical supervision.

5-Prof. Sanjay Khattri* (MD): Concept and study design, overall supervision of the study, final approval of the manuscript.

\section{CONFLICT OF INTERESTS}

All authors declare that they have no conflict of interest. Compliance with Ethics Guidelines: All procedures performed in studies involving human participants were in accordance with the ethical standards of the institutional and/or national research committee.

\section{REFERENCES}

1. Methodology WHOIWG for DS, Methodology WHOCC for DS, Services WHOCC for DUR and CP. Introduction to drug utilization research [Internet]. Geneva PP-Geneva: World Health Organization; Available from https://apps. who. int/iris/handle/10665/42627. Accessed: 2020-09-07.

2. Reder BL, Nielsen SL, Magnussen P, Engquist A, Frimodt-Møller N. Antibiotic usage in an intensive care unit in a Danish university hospital. J Antimicrob Chemother. 1993;32:633-42.

3. Esposito S, Leone S. Antimicrobial treatment for Intensive Care Unit (ICU) infections including the role of the infectious disease specialist. International journal of antimicrobial agents. 2007;29:494-500.

4. Lockhart SR, Abramson MA, Beekmann SE, Gallagher G, Riedel S, Diekema DJ, et al. Antimicrobial resistance among gram-negative bacilli causing infections in intensive care unit patients in the United States between 1993 and 2004. J Clin Microbiol. 2007;45:3352-9.

5. Weber RJ, Kane SL, Oriolo VA, Saul M, Skledar SJ, Dasta JF. Impact of intensive care unit (ICU) drug use on hospital costs: a descriptive analysis, with recommendations for optimizing ICU pharmacotherapy. Crit Care Med. 2003;31:S17-24.

6. MD MHK, Ward S. The Influence of Mini-BAL Cultures on Patient Outcomes: Implications for the Antibiotic Management of VentilatorAssociated Pneumonia. Chest [Internet]. 1998;113:412-20.

7. Global Risks Report 2011. World Economic Forum. Available from: https://www. weforum. org/reports/global-risks-report2011. Accessed: 2020-09-07

8. Paterson DL, Rogers BA. How soon is now? The an urgent need for randomized, controlled trials evaluating the treatment of multidrugresistant bacterial infection. Clin Infect Dis. 2010;51:1245-7.

9. Archibald L, Phillips L, Monnet D, McGowan JE, Tenover F, Gaynes R. Antimicrobial resistance in isolates from inpatients and outpatients in the United States: Increasing importance of the intensive care unit. Clin Infect Dis. 1997;24:211-5.

10. WHO ATC/DDD Index 2016. Available from: http//www. whocc. no/atc_ddd_index./.Accessed: 2016-09-12.
11. Brunton L, Chamber B, Knollman B, editors. Goodman and Gilman's the Pharmacological Basis of Therapeutics. 12th ed. New York: McGraw-Hill; 2011. p. 1365-81.

12. Shankar PR, Upadhyay DK, Subish P, Bhandari RB, Das B. Drug utilisation among older inpatients in a teaching hospital in western Nepal. Singapore Med J. 2010;51:28-34.

13. Patel MK, Barvaliya MJ, Patel TK TC. Drug utilization pattern in critical care unit in a tertiary care teaching hospital in India. Int J Crit Illn Inj Sci. 2013;3:250.

14. Curcio DJ, Curcio D, Alí A, Duarte A, Defilippi Pauta A, Guerrón $\mathrm{AFE}$, et al. Antibiotic prescription in intensive care units in Latin America. Rev Argent Microbiol. 2011;43:203-11.

15. Anand N, Nagendra Nayak IM, Advaitha M V, Thaikattil NJ, Kantanavar KA, Anand S. Antimicrobial agents' utilization and cost pattern in an Intensive Care Unit of a Teaching Hospital in South India. Indian J Crit care Med peer-reviewed, Off Publ Indian Soc Crit Care Med. 2016;20:274-9.

16. Smythe MA, Melendy SU, Jahns BR, Dmuchowski CA. An exploratory analysis of medication utilization in a medical intensive care unit. Critical care medicine. 1993;21:1319-23.

17. Tavallaee M, Fahimi F, Kiani S. Drug-use patterns in an intensive care unit of a hospital in Iran: an observational prospective study. Int J Pharm Pract. 2010 Dec; 18(6):370-6.

18. Williams A, Mathai AS, Phillips AS. Antibiotic prescription patterns at admission into a tertiary level intensive care unit in Northern India. J Pharm Bioallied Sci. 2011;3:531-6.

19. Paul N, Santhosh Kumar V. A comparative study on drug use of antimicrobial agents in medical and surgical intensive care units of a tertiary care hospital. Asian J Pharm Clin Res. 2018;11:310-3.

20. Bitterman R, Hussein K, Leibovici L, Carmeli Y, Paul M. Systematic review of antibiotic consumption in acute care hospitals. Clin Microbiol Infect Off Publ Eur Soc Clin Microbiol Infect Dis. 2016;22:561. e7-561. e19.

21. Intensive Care Antimicrobial Resistance Epidemiology (ICARE) Surveillance Report, data summary from January 1996 through December 1997:A report from the National Nosocomial Infections Surveillance (NNIS) System. Am J Infect Control. 1999;27:279-84.

22. Adeli O, Markazi Moghaddam N, Hamidi Farahani R, Zargar Balaye Jame S. Antibiotics use patterns in intensive care units of five hospitals in Tehran during 2011-2012. Journal of Archives in Military Medicine. 2015;3:e27862.

23. Meyer E, Jonas D, Schwab F, Rueden H, Gastmeier P, Daschner FD. Design of a surveillance system of antibiotic use and bacterial resistance in German intensive care units (SARI). Infection. 2003;31:208-15.

24. Inan D, Saba R, Gunseren F, Ongut G, Turhan O, Yalcin AN, et al. Daily antibiotic cost of nosocomial infections in a Turkish university hospital. BMC Infect Dis. 2005;5:1-6.

25. Amit GS. Drug Use Evaluation Study in a Tertiary Care Corporate Hospital with Special Reference to Use of Antibiotics in ICU Department. Int J Adv Pharmacy, Biol Chem. 2013;2:179-89.

26. Mangrulkar VS, Mangrulkar S, Khair P PA. Antibiotic Use in the Intensive Care Unit. J Assoc Physicians India. 2012;60:15-8.

27. Vandijck DM, Depaemelaere M, Labeau SO, Depuydt PO, Annemans L, Buyle FM, et al. Daily cost of antimicrobial therapy in patients with Intensive Care Unit-acquired, laboratory-confirmed bloodstream infection. Int J Antimicrob Agents. 2008;31:161-5.

28. John LJ, Devi P, John J, Guido S. Drug utilization study of antimicrobial agents in medical intensive care unit of a tertiary care hospital. Asian J Pharm Clin Res. 2011;4:81-4. 